\title{
Assessment of the prevalence of Respiratory Symptoms among the Workers of Automobile Industry
}

\author{
Andleeb Shariq ${ }^{1}$, Shazaib Akhtar ${ }^{2}$, Bilal Nazar ${ }^{3}$ \\ 1.House Officer Allama Iqbal Memorial teaching Hospital, Sialkot \\ 2. House Officer, Services Institute of Medical Sciences, Lahore \\ 3. House Officer, Nishtar Hospital, Multan \\ Corresponding Author: dr.andleebshariq@gmail.com
}

\begin{abstract}
:
Objective: To assess the prevalence of respiratory system symptoms among the workers of automobile industry who are frequently exposed to hazardous chemical agent and dust. Study Design: Cross-sectional observational study. Place and Duration of Study: Nishtar Hospital Multan, Bahawal Victoria hospital Bahawalpur. from August 2018 to March 2019. Methodology: Sixty eight participants of which 34 were exposed and 34 were nonexposed workers of an automobile factory were selected. Age, BMI, smoking history, lung functions including $\mathrm{FEV}_{1}, \mathrm{FVC}, \mathrm{FEV} 1 / \mathrm{FVC}, \mathrm{PEF}, \mathrm{PEF}_{25-75}$ and $\mathrm{VC}$ before and after the work shift, symptoms including dry throat, runny nose, headache, fatigue, cough, phlegm, dyspnea, and wheeze; and chest tightness were compared between the cases and controls. Independent t-test, paired t-test and chi-square tests were applied. Data was analyzed with SPSS v.23.0 after considering $\mathrm{p}<0.05$ statistically significant. Results: $\mathrm{FEV}_{1}, \mathrm{PEF}$, and VC were significantly decreased in the exposed workers as compared those who were not exposed (p-value $<0.001$, $<0.001$ and 0.001 , respectively). The decrease in FVC and FEV1/FVC and FEV1/VC ratio was also significant (p-value $0.011,0.002$ and 0.048 , respectively). Dry throat, runny nose and fatigue were significantly more in cases (p-value 0.022, 0.016 and 0.018, respectively). Cough, phlegm, wheeze, and dyspnea; and chest tightness were more prevalent in the cases (p-value $0.015,<0.001,0.001,<0.001$ and 0.001 , respectively). Conclusion: Decline in lung functions and prevalence of respiratory symptoms were significant in the workers exposed to dust and BTEX warranting the performance of lung function tests before and after the employment for the identification of the sensitive personnel.
\end{abstract}

Keywords: automobile factories, respiratory symptoms, prevalence.

DOI: $10.7176 / \mathrm{JMPB} / 65-07$

Publication date: April $30^{\text {th }} 2020$

\section{Introduction:}

In exposed workers of small as well as larger scale industries, many respiratory disorders are caused due to the inhalation of dust particles and various chemical agents ${ }^{1,2}$. It is the type of dust particles, gases, vapors inhaled along with the time period of exposure which determine the development of the type of respiratory symptoms by the dust, gases and the vapors in the occupational settings ${ }^{3,4}$. Respiratory disorders and the symptoms can be prompted due to the exposure of the workers to the polluting agent ${ }^{5,6}$. Residents and the workers of the industrial are can probably experience acute exposure to the disease causing polluting agents. In the following months, these workers and the residents experience chronic exposure ${ }^{7}$. In many studies, the prevalence of various respiratory symptoms such as dyspnea, chronic cough, chest tightness and rhinitis has been highlighted in the population exposed to pollutants in comparison with the controls ${ }^{8-10}$.

Hanssen et al. ${ }^{11}$ highlighted the high prevalence of respiratory signs and symptoms in the workers present inside the green house when compared with the controls. Pesticides and tobacco smoke have high tendency to cause possible health hazards related to the respiratory system ${ }^{12-14}$. The observed relationship between the occurrence of respiratory symptoms and tobacco smoking was significant ${ }^{15}$. While the association of the respiratory symptoms with the spirometry results has been shown to be minimal ${ }^{7}$. The effects of dust exposure over the respiratory symptoms has been documented in some research studies ${ }^{16}$. Dust affects many organs of the body including eyes, nose, lungs and the airways and it has a strong tendency to cause the respiratory complications in the laborers who are exposed at the work places ${ }^{17}$.

Chemicals present at different workplaces irritate the airways and sensitize the airway epithelium which results in the development of many respiratory illnesses and lung functions are significantly affected ${ }^{18}$. Many volatile organic substances are toxic and can cause different type of hematologic effects, induction of carcinogenesis and 
nervous system disorders. Increase in the greenhouse effect had played a significant role in the emergence of respiratory system disorders, recently. The International Agency for Research on Cancer (IARC) and Environmental Protection Agency (EPA) have classified benzene as human carcinogen because it has been found to cause cancer in both the humans and the animals ${ }^{3,19-21}$. The exposure of the workers to dust and organic harmful agents such as chlorinated hydrocarbons, PAHs and PTEX is common is common and this all has detrimental effect on the respiratory system ${ }^{16}$.

Although many studies have been conducted on respiratory system disorders, very few have showed that there is mild difference in the lung functions prior to and after the employment in the automobile factories. Moreover, there has been observed inflation in the installment of automobile factories in Pakistan in the recent past but the data about the workers' health has been insufficient. Current study is aimed at observing the prevalence of the respiratory system disorders as well as symptomatology among the works who are working at automobile factories in Pakistan and are frequently exposed to dust and BTEX (benzene, toluene, ethyl benzene and xylene).

\section{Material and methodology:}

This is a cross-sectional observational study which was conducted in Nishtar Hospital Multan, Bahawal Victoria hospital Bahawalpur. from August 2018 to March 2019. Sample size was calculated after taking the study by Harati B et al. ${ }^{22}$ as reference. We selected sixty eight participants in our study out of which, thirty four were the workers who were exposed to different levels of the BTEX whereas other thirty four were the controls who were not exposed to BTEX but were working at the factory. We evaluated sixty eight samples to evaluate the respiratory symptoms as well as the lung functions. We selected only those workers who were working during the morning shift. The exposure time of the workers to the pollutants was approximately 1 to 8 hours per day. All the workers who were known cases of COPD, previously diagnosed of sinusitis, lung carcinoma and were asthmatic were excluded from the study. All the participants were fully informed about the nature of our study and proper written consent was taken.

NIOSH method was used to obtain analyze the sample of the inhaled air for the presence of BTEX compounds. We collected 60 samples in about 8 hours in the morning shift. To collect the air samples, sir was aspirated through specific sampling tubes which contained activated coconut shell charcoal. The flow rate of the battery operated samplers used to collect the air samples was $100 \mathrm{ml}$ per minute. Pumps with stable flow rate were preferred for prolonged sapling over a time period of eight hours. We performed tests to assess pulmonary function in sixty eight subjects, thirty four cases and thirty four controls. We used spirometer, disposable mouth piece filters and nose clips in both the exposed as well as non-exposed workers for the evaluation of lung functions. We performed spirometry tests before the start of the work shift and then after two days absence from work. The test performed to assess lung function included forced expiratory volume during $1^{\text {st }}$ second (FEV1), forced vital capacity (FVC), forced expiratory volume during $1^{\text {st }}$ second to forced vital capacity ratio (FEV1/FVC), peak expiratory flow (PEF), peak expiratory flow mid quartile average $\left(\mathrm{PEF}_{25-75}\right)$ and vital capacity (VC). Pulmonary functions tests of the cases and the controls were compared before and after the work shift.

A proper questionnaire was set and the data about smoking history, non-specific symptoms and the respiratory symptoms was collected by the researcher himself. The non-specific symptoms included dry throat, runny nose, headache and fatigue; and the respiratory symptoms included cough, phlegm, dyspnea, and wheeze; and chest tightness. The prevalence of these symptoms was compared between the cases and the controls. All the data was analyzed using the software SPSS version. 23.0. The mean age and BMI was compared by independent t-test. Pulmonary function tests were compared by applying paired test. Pearson chi-square test was applied to compare smoking history and symptomatology. P-value of less than 0.05 was considered statistically significant.

\section{Results:}

Age and BMI of thirty four cases and thirty four controls were not significantly different ( $>0.05) .53 \%$ of the cases and $41 \%$ of the controls were smokers, the difference being statistically insignificant ( $\mathrm{p}>0.05)$. Table-I

Average levels BTEX were calculated after collecting various samples. (Table-II) The difference in lung function tests before and after the work shift were compared between the two groups. FEV1, peak expiratory flow (PEF), and vital capacity (VC) were significantly decreased in the exposed workers as compared those who were not exposed (p-value $<0.001,<0.001$ and 0.001 , respectively). The decrease in forced vital capacity (FVC) and FEV1/FVC ratio was also significant (p-value 0.011 and 0.002 , respectively). Apparently, the difference in the FEV1/VC ratio was not different between the two groups but it was still statistically significant $(p=0.048)$. Table-III 
The complaint of headache was not different in the two groups $(\mathrm{p}=0.056)$. Other non-specific symptoms including dry throat, runny nose and fatigue was complained by $35 \%, 32 \%$ and $44 \%$ of the cases; and $12 \%, 9 \%$ and $18 \%$ of the controls, respectively. The difference was statistically significant (p-value $0.022,0.016$ and 0.018 , respectively). The respiratory system symptoms including cough, phlegm, wheeze, dyspnea and chest tightness were complained by $41 \%, 53 \%, 35 \%, 44 \%$ and $38 \%$ of the cases; and $15 \%, 6 \%, 3 \%, 6 \%$ and $6 \%$ of the controls. The difference in the prevalence of these respiratory symptoms was also statistically significant (pvalue $0.015,<0.001,0.001,<0.001$ and 0.001 , respectively). Table-IV

Table-I

Demographic and Baseline Data of the Patients

\begin{tabular}{|l|c|c|c|}
\hline \multicolumn{1}{|c|}{ Variable } & Cases $(\mathbf{n}=\mathbf{3 4})$ & Controls $(\mathbf{n}=\mathbf{3 4 )}$ & p-value \\
\hline Age & $33.12 \pm 9.71$ & $31.65 \pm 9.53$ & 0.531 \\
\hline BMI & $24.56 \pm 2.62$ & $23.97 \pm 1.71$ & 0.278 \\
\hline Smoking, $\mathrm{n}(\%)$ & $18(53)$ & $14(41)$ & 0.331 \\
\hline
\end{tabular}

Data is presented as mean \pm S.D unless indicated otherwise. Independent t-test and Pearson chi-square test applies.

Table-II

Exposure levels of BTEX in factory workers

\begin{tabular}{|c|c|c|c|c|}
\hline Levels & Benzene & Toluene & Ethyl benzene & Xylene \\
\hline Current day level $(\mathrm{ppm})$ & $0.74 \pm 0.12$ & $2.17 \pm 2.9$ & $41.24 \pm 3.1$ & $34.11 \pm 26.2$ \\
\hline Four-week Average (ppm) & $0.76 \pm 0.14$ & $1.41 \pm 1.8$ & $47.68 \pm 7.4$ & $43.34 \pm 22.7$ \\
\hline Cumulative (ppm, years) & $0.59 \pm 0.21$ & $1.49 \pm 2.3$ & $53.47 \pm 11.5$ & $53.85 \pm 28.1$ \\
\hline
\end{tabular}

Data is presented as mean \pm S.D.

Table-III

Lung function tests before and after employment

\begin{tabular}{|c|c|c|c|c|c|}
\hline \multirow[b]{2}{*}{ Parameter } & \multicolumn{2}{|c|}{ Cases $(n=34)$} & \multicolumn{2}{|c|}{ Controls $(n=34)$} & \multirow[b]{2}{*}{ p-value } \\
\hline & Before & After & Before & After & \\
\hline FEV1 (L) & $4.80 \pm 0.31$ & $4.32 \pm 0.32$ & $4.66 \pm 0.23$ & $4.60 \pm 0.23$ & $<0.001$ \\
\hline FVC (L) & $3.90 \pm 0.45$ & $3.72 \pm 0.44$ & $3.99 \pm 0.28$ & $3.81 \pm 0.35$ & 0.011 \\
\hline FEV1/FVC $\%$ & $79.44 \pm 4.09$ & $77.56 \pm 3.84$ & $81.41 \pm 4.07$ & $78.59 \pm 4.31$ & 0.002 \\
\hline PEF (L/S) & $9.15 \pm 0.21$ & $8.81 \pm 0.22$ & $8.99 \pm 0.19$ & $9.02 \pm 0.18$ & $<0.001$ \\
\hline $\mathrm{PEF}_{25-75}(\mathrm{~L} / \mathrm{S})$ & $4.42 \pm 0.28$ & $3.81 \pm 0.46$ & $4.28 \pm 0.32$ & $3.61 \pm 0.29$ & $<0.001$ \\
\hline $\mathrm{VC}(\mathrm{L})$ & $4.75 \pm 0.20$ & $4.61 \pm 0.13$ & $4.66 \pm 0.14$ & $4.65 \pm 0.12$ & 0.001 \\
\hline FEV1/VC (\%) & $81.41 \pm 3.12$ & $80.38 \pm 2.90$ & $81.65 \pm 4.01$ & $79.74 \pm 5.33$ & 0.048 \\
\hline
\end{tabular}

Data is presented as mean \pm S.D. Paired t-test applied.

Table-IV

\section{Respiratory Symptoms}

\begin{tabular}{|l|c|c|c|}
\hline \multicolumn{1}{|c|}{ Variable } & Cases $(\mathbf{n}=\mathbf{3 4})$ & Controls (n=34) & p-value \\
\hline Dry throat, n (\%) & $12(35)$ & $4(12)$ & 0.022 \\
\hline Running nose, n (\%) & $11(32)$ & $3(9)$ & 0.016 \\
\hline Cough, n (\%) & $14(41)$ & $5(15)$ & 0.015 \\
\hline Fatigue, n (\%) & $15(44)$ & $6(18)$ & 0.018 \\
\hline Headache, n (\%) & $9(26)$ & $3(9)$ & 0.056 \\
\hline Phlegm, n (\%) & $18(53)$ & $2(6)$ & $<0.001$ \\
\hline Wheeze, n (\%) & $12(35)$ & $1(3)$ & 0.001 \\
\hline Dyspnea, n (\%) & $15(44)$ & $2(6)$ & $<0.001$ \\
\hline Chest tightness, n (\%) & $13(38)$ & $2(6)$ & 0.001 \\
\hline
\end{tabular}




\section{Discussion:}

Exposure to airborne chemicals, biological pollutants and dust results in severe effects on the health of the workers ${ }^{12,16}$. In the study conducted by Harati B et al. ${ }^{22}$, a decrease in the lung functioning capacity and a rise in the prevalence of the respiratory symptoms was observed among the workers who were exposed to BTEX chemicals and dust at an automobile manufacturing factory in Tehran, Iran. These results were consistent with the results observed in current study. Similar study was conducted by Gosh T et al. ${ }^{23}$ and they observed similar effects on the health of the personnel working at a rice mill in India. A consistent correlation of self-reported exposure at the workstation with the respiratory symptoms and lung disorder has been observed ${ }^{24-26}$. But the worth of the questionnaire used for research purpose depends on the local and regional cultures ${ }^{27}$. Lung function tests are found to be more reliable criteria instead of the questionnaire for the detection of chronic obstructive pulmonary diseases ${ }^{28}$.

In the current study, a decrease in the lung functioning capacity and a rise in the prevalence of the respiratory symptoms were observed among the workers who were exposed to BTEX chemicals and dust at the automobile factory. The prevalence of cough, wheeze, phlegm, dyspnea and chest tightness was found to be high in the exposed workers. Prevalence of respiratory symptoms among the exposed workers indicate the increased risk of respiratory diseases ${ }^{9}$.Almost $4-21 \%$ increase in wheezing and $4-8 \%$ increase in shortness of breath was observed in the farmers who were involved in the production of crops ${ }^{29}$. In other studies conducted on different types of workers who were commonly exposed to dust, forced vital capacity (FVC), vital capacity (VC) and peak expiratory flow (PEF) were detected to be significantly lower than those of the controls ${ }^{30-33}$.

In the polluted workstation, the use of a proper questionnaire is recommended for the detection of the sensitive personnel before the start of job. Worker having pre-existing pulmonary diseases and lung pathologies may be at higher risk of developing acute and chronic pulmonary diseases if they continue their work in the polluted environment of the factories.

\section{Conclusion:}

Decline in lung functions and prevalence of non-specific and respiratory symptoms was significant in the workers exposed to dust and BTEX. This warrants the performance of lung function tests before and after the employment for the identification of the sensitive personnel.

Conflict of interest: There was no conflict of interest found regarding this research.

Funding Source: No funding source was available for this study.

\section{References:}

1. Skórska C, Mackiewicz B, Dutkiewicz J. Effects of exposure to flax dust in Polish farmers: work-related symptoms and immunologic response to microbial antigens associated with dust. Ann Agric Environ Med. 2000;7(2):111-8.

2. Mackiewicz B, Skórska C, Dutkiewicz J. Relationship between concentrations of microbiological agents in the air of agricultural settings and occurenceof work-related symptoms in exposed persons. Ann Agric Environ Med. 2015;22(3).

3. Axelsson G, Barregard L, Holmberg E, Sallsten G. Cancer incidence in a petrochemical industry area in Sweden. Sci Total Environ. 2010;408(20):4482-7.

4. Aminian O, Aslani M, Haghighi KS. Cross-shift study of acute respiratory effects in cement production workers. Acta Medica Iranica. 2014;52(2):146.

5. Lombardo LJ, Balmes JR. Occupational asthma: a review. Environ Health Perspect. 2000;108(Suppl 4):697.

6. Mirabelli MC, London SJ, Charles LE, Pompeii LA, Wagenknecht LE. Occupation and three-year incidence of respiratory symptoms and lung function decline: the ARIC Study. Resp Res. 2012;13(1):24.

7. Maslow $\mathrm{CB}$ et al. Chronic and acute exposures to the world trade center disaster and lower respiratory symptoms: area residents and workers. Am J Public Health. 2012;102(6):1186-94.

8. Mons E. Occupational asthma in greenhouse workers. Curr Opin Pulm Med. 2004;10(2):147-50.

9. Tual S, Clin B, Levêque-Morlais N, Raherison C, Baldi I, Lebailly P (2013). Agricultural exposures and chronic bronchitis: findings from the AGRICAN (AGRIculture and CANcer) cohort. Ann Epidemiol, 23(9):539-45. 
10. Adhikari A, et al. Airborne microorganisms, endotoxin, and $(1 \rightarrow 3)-\beta$-D-glucan exposure in greenhouses and assessment of respiratory symptoms among workers. Ann Occup Hygiene. 2010;55(3):272-85.

11. Hanssen VM, Nigatu AW, Zeleke ZK, Moen BE, Bråtveit M. High prevalence of respiratory and dermal symptoms among Ethiopian flower farm workers. Arch Environ Occup Health. 2015;70(4):204-13.

12. Kearney GD, et al. The association of respiratory symptoms and indoor housing conditions among migrant farmworkers in eastern North Carolina. J Agromedicine. 2014;19(4):395-405.

13. Stosic L, Milutinovic S, Lazarevic K, Blagojevic L, Tadic L. Household environmental tobacco smoke and respiratory diseases among children in Nis (Serbia). Cent Eur J Public Health. 2012;20(1):29.

14. Xu X, Nembhard WN, Kan H, Becker A, Talbott EO. Residential pesticide use is associated with children's respiratory symptoms. J Occup Environ Med. 2012;54(10):1281-7.

15. Smith TJ, et al. E (2006). Overview of particulate exposures in the US trucking industry. J Environ Monit, 8(7):711-20.

16. Musa R, Naing L, Ahmad Z, Kamarul Y. Respiratory health of rice millers in Kelantan, Malaysia.

17. Dewangan KN, Patil MR. Evaluation of Dust Exposure among the Workers in Agricultural Industries in North-East India. Ann Occup Hygiene. 2015;59(9):1091-105.

18. Nemer M, Kristensen P, Nijem K, Bjertness E, Skare Ø, Skogstad M. Lung function and respiratory symptoms among female hairdressers in Palestine: a 5-year prospective study. The Lancet. 2017;390:S6.

19. Gariazzo C, Pelliccioni A, Di Filippo P, Sallusti F, Cecinato A. Monitoring and analysis of volatile organic compounds around an oil refinery. Water, air, and soil pollution. 2005;167(1-4):17-38.

20. Maghsoodi Moghadam R, Bahrami A, Ghorbani F, Mahjub H, Malaki D. Investigation of qualitative and quantitative of volatile organic compounds of ambient air in the Mahshahr petrochemical complex in 2009. J Res Health Sci. 2013;13(1):69-74.

21. Thepanondh S, Varoonphan J, Sarutichart P, Makkasap T. Airborne volatile organic compounds and their potential health impact on the vicinity of petrochemical industrial complex. Water, Air, \& Soil Pollution. 2011;214(1-4):83-92.

22. Harati B, et al. Evaluation of Respiratory Symptoms among Workers in an Automobile Manufacturing Factory, Iran. Iran J Public Health. 2018;47(2):237.

23. Ghosh T, Gangopadhyay S, Das B. Prevalence of respiratory symptoms and disorders among rice mill workers in India. Environ Health Prevent Med. 2014;19(3):226.

24. Jayet PY, et al. Passive smoking exposure among adults and the dynamics of respiratory symptoms in a prospective multicenter cohort study. Scand J Work Environ Health. 2005:465-73.

25. Laden F, Chiu YH, Garshick E, Hammond SK, Hart JE. A cross-sectional study of secondhand smoke exposure and respiratory symptoms in non-current smokers in the US trucking industry: SHS exposure and respiratory symptoms. BMC Public Health. 2013;13(1):93.

26. Pilkington PA, Gray S, Gilmore AB. Health impacts of exposure to second hand smoke (SHS) amongst a highly exposed workforce: survey of London casino workers. BMC Public Health. 2007;7(1):257.

27. Cullinan P, Newman Taylor A. Asthma: environmental and occupational factors. Br Med Bull. 2003;68(1):227-42.

28. Buffels J, Degryse J, Heyrman J, Decramer M. Office spirometry significantly improves early detection of COPD in general practice: the DIDASCO Study. Chest. 2004;125(4):1394-9.

29. Mirabelli MC, Hoppin JA, Chatterjee AB, Isom S, Chen H, Grzywacz JG, Howard TD, Quandt SA, Vallejos QM, Arcury TA. Job activities and respiratory symptoms among farmworkers in North Carolina. Arch Environ Occup Health. 2011;66(3):178-82.

30. Kakooei H, Marioryad H. Exposure to inhalable flour dust and respiratory symptoms of workers in a flour mill in Iran.

31. Meo SA. Dose responses of years of exposure on lung functions in flour mill workers. J Occup Health. 2004;46(3):187-91

32. Meo SA, Al-Drees AM. Lung function among non-smoking wheat flour mill workers. Int J Occup Med Environ Health. 2005;18(3):259-64.

33. Neghab M, Soltanzadeh A, Alipour A. Relationship between spirometry results and respiratory complaints to flour dust in flour mill workers. Iran Occup Health. 2010;7(2):45-51. 